\title{
Fusarium poae Pathogenicity and Mycotoxin Accumulation on Selected Wheat and Barley Genotypes at a Single Location in Argentina
}

\author{
Sebastian A. Stenglein and María I. Dinolfo, Laboratorio de Biología Funcional y Biotecnología (BIOLAB)-CICBA-INBIOTEC, \\ CONICET, Facultad de Agronomía de Azul, UNCPBA, 7300 Azul, Buenos Aires, Argentina. Germán Barros, Departamento de Micro- \\ biología e Inmunología, UNRC, CONICET, 5800 Río Cuarto, Córdoba, Argentina; Fabricio Bongiorno, Cátedra de Estadística y \\ Diseño Experimental, Facultad de Agronomía de Azul, UNCPBA; Sofía N. Chulze, Departamento de Microbiología e Inmunología, \\ UNRC, CONICET; and María V. Moreno, Laboratorio de Biología Funcional y Biotecnología (BIOLAB)-CICBA-INBIOTEC, \\ CONICET, Cátedra de Microbiología, Facultad de Agronomía de Azul, UNCPBA
}

\begin{abstract}
Stenglein, S. A., Dinolfo, M. I., Barros, G., Bongiorno, F., Chulze, S. N., and Moreno, M. V. 2014. Fusarium poae pathogenicity and mycotoxin accumulation on selected wheat and barley genotypes at a single location in Argentina. Plant Dis. 98:1733-1738.

Fusarium poae is a relatively weak pathogen with increasing importance in cereal grains, principally due to its capacity to produce several mycotoxins. In this study, we evaluated the pathogenicity and toxin accumulation of individual $F$. poae isolates on wheat and barley under natural conditions for 3 years. Analysis of variance demonstrated significant differences for year-genotype, year-isolate, genotypeisolate, and year-genotype-isolate interactions for both incidence and disease severity. Based on contrast analysis, 'Apogee' was more susceptible than the other wheat genotypes, wheat genotypes were more

susceptible than barley genotypes, durum wheat genotypes were more susceptible than bread wheat genotypes, and barley genotype 'Scarlett' had greater symptom development per spike than the other barley genotypes. Neither HT-2 nor T-2 toxins were detected in the grain samples. However, high levels of nivalenol were found in both wheat and barley samples. The increased reported isolation of $F$. poae from wheat and barley and the high capacity of this fungus to produce nivalenol underlie the need for more studies on $F$. poae-host interactions, especially for barley.
\end{abstract}

Fusarium head blight (FHB) or scab is an insidious disease of wheat (both Triticum aestivum and T. durum) and barley (Hordeum vulgare) that not only reduces grain quality and yield but also may cause kernel contamination with mycotoxins.

Wheat and barley are the two most important winter crops in Argentina. Production of these grains is for both export and local consumption, with bread wheat for bread, durum wheat for noodles, barley for malting, and all for animal feed.

Although Fusarium graminearum Schwabe is the predominant FHB agent worldwide on small cereal grains, F. culmorum (Wm. G. Sm.) Sacc., F. avenaceum (Fr.) Sacc., and F. poae (Peck) Wollenw. are commonly isolated. In recent years, changes in the frequency or abundance of Fusarium spp. have been observed $(17,18,34)$. Some studies suggest that this variability may be due, in part, to environmental or agronomic practices. For example, $\mathrm{Xu}$ et al. (33) observed that Fusarium spp. variation depend on environmental variables such as warmer, drier, or more humid conditions, whereas Fernandez et al. (15) associated Fusarium spp. variation with production practices such as crop rotation, tillage systems, and herbicide use, among others.

Fusarium spp. populations are studied continuously in different countries, on different hosts, or in different conditions. F. poae is a relatively weak pathogen with a high frequency of isolation in cereal surveys in recent years, such as Argentina, Canada, Germany, and Italy, among other countries $(5,6,9,17,28)$.

Mycotoxins can cause adverse effects in humans and animals through ingestion of contaminated cereal grains, where trichothecenes (inhibitors of eukariotic protein synthesis) are considered the most important toxins produced by Fusarium spp. $(4,12)$. Among the mycotoxins produced by $F$. poae, nivalenol (NIV), a type B

Corresponding author: S. A. Stenglein, E-mail: stenglein@faa.unicen.edu.ar

Accepted for publication 16 June 2014.

http://dx.doi.org/10.1094/PDIS-02-14-0182-RE

(C) 2014 The American Phytopathological Society trichothecene, was cited as one of the most common mycotoxins produced by this fungus $(19,32,35)$. Moreover, $F$. poae can produce trichothecenes of type A such as T-2 and HT-2, among others (30).

Strategies that contribute to prevent or reduce FHB include inoculum reduction through agronomic practices and the use of germplasm with improved levels of tolerance $(14,15)$. In this way, different studies were conducted to analyze the $F$. graminearumwheat or-barley interactions $(1,20)$. However, few studies about $F$. poae-wheat or -barley interactions or toxin grain accumulation are available $(7,29,32)$.

The hypothesis of this study was that the response and accumulation of NIV, HT-2, and T-2 toxins of selected wheat (bread and durum) and barley genotypes inoculated with $F$. poae are genotype and isolate dependent.

\section{Materials and Methods}

Inoculum production. Four monosporic $F$. poae isolates isolated from bread wheat (TSS1a, TSa1a, MICAT01, and MICAT08) and one isolate obtained from barley grains (HSula), all confirmed previously by a polymerase chain reaction (PCR) species-specific assay and with the potential to produce NIV, were used individually in this study $(10,11)$. Fungal inoculum was produced by placing individual agar plugs with mycelium and conidia onto potato dextrose agar (PDA; Britania) in petri dishes ( 90 by $20 \mathrm{~mm}$ ) and incubating for 7 days at $25 \pm 2{ }^{\circ} \mathrm{C}$ under $12 \mathrm{~h}$ each of light and darkness. The conidial harvest was done by flooding the plates with $5 \mathrm{ml}$ of sterilized distilled water (SDW) and dislodging the conidia with a bent glass rod. The resulting suspension was filtered through cheesecloth and the conidial suspension was adjusted to 1 $\times 10^{5}$ conidia/ml with a Neubauer hemacytometer and binocular stereoscope. Tween $20(0.05 \%)$ was added to the suspension as a surfactant.

Field assays and experimental design. Five wheat genotypes were used for this study: 'Apogee' (bread wheat), susceptible to $F$. poae (32); 'Klein Chajá' (bread wheat); 'Buck Biguá' (bread wheat); 'Chagual' (durum wheat); and 'Cumenai' (durum wheat). The three barley genotypes included in the study were 'Scarlett' (the two-row barley genotype sown by most growers in Argentina), 
'Barke' (two-row), and 'B1215' (two-row). Seed of each genotype were surface-disinfected by soaking in $50 \%$ ethanol for $3 \mathrm{~min}$ and sodium hypochlorite (commercial $55 \mathrm{~g} /$ liter) for $3 \mathrm{~min}$, then rinsed three times with SDW.

Field assays were carried out on the experimental farm at the Faculty of Agronomy, Azul, Buenos Aires province, Argentina $\left(36^{\circ} 49^{\prime} 53^{\prime \prime} \mathrm{S}, 59^{\circ} 53^{\prime} 23^{\prime \prime} \mathrm{W}\right)$. The soil is a typical Argiudoll and conventional tillage operations (once with a disc plow and harrow to a depth of $15 \mathrm{~cm}$ ) were made in all years.

The field experiment was a randomized complete block design with three replicates, where the 40 treatments (eight genotypes by five isolates) were randomized for each block. Each plot size was 1 by $0.4 \mathrm{~m}$ and genotypes were sown at 350 seeds $/ \mathrm{m}^{2}$. The distance between plots was $1 \mathrm{~m}$. The field trials were done during the 2009, 2010, and 2012 harvest seasons, without supplemental irrigation. Sowing dates ranged from 7 to 20 July in the 3 years because they were adjusted for the different genotypes to ensure uniformity in timing of inoculum applications. This adjustment was based on previous observations in 2007 and 2008 of the growth stages of these genotypes. Plants were grown in the absence of any nutritional or pest stress, except that no fungicide treatments were applied. Temperature, relative humidity, and precipitation data (from inoculation to harvest during 2009, 2010, and 2012) were obtained from the National Meteorological Center-weather station, located $100 \mathrm{~m}$ from the experimental site (Table 1).

Complete plots were inoculated. Wheat heads were inoculated in mid-anthesis according to Vogelgsang et al. (32) and barley when $>50 \%$ of the plants had reached anthesis according to Buerstmayr et al. (8). Conidial suspensions of each fungal isolate were applied until run-off using a gravity spray gun. SDW with Tween 20 was used to inoculate and served as control treatment.

Visual disease assessment (incidence, number of spikes with symptoms, and severity, number of spikelets with symptoms per spike) was conducted at 20 days postinoculation by counting the number of symptomatic grains (lesions or bleaching of grains or glumes with a dark margin) of 30 spikes/plot selected at random. Blocks were combine threshed in December and cleaned manually.

To check the possibility of contamination with other Fusarium spp., 50 grains/block were surface disinfected (70\% ethanol for 2 min and 5\% sodium hypochlorite for $2 \mathrm{~min}$, then finally rinsed twice in SDW) and placed on PDA with $0.25 \mathrm{~g}$ of chloramphenicol and incubated for 7 days at $25 \pm 2{ }^{\circ} \mathrm{C}$ under $12 \mathrm{~h}$ each of light and darkness. Fusarium spp. were identified according to Leslie and Summerell (21). For mycotoxin assessment, a subsample of $25 \mathrm{~g}$ was obtained using a grain divider and ground with a sample mill.

Data analyses. For incidence and severity, combined analyses across years, plant genotypes, isolates, and the interactions were subjected to an analysis of variance (ANOVA) using version 2012 of the INFOSTAT software (13). The experiment was analyzed as a factorial design with years, genotypes, and isolates as factors. Percentage data (incidence and severity) were transformed using the arcsin square root function before ANOVA. Contrasts were performed between Apogee (used as susceptible control) versus the other wheat genotypes, wheat versus barley genotypes, durum versus bread wheat genotypes, and Scarlett versus B1215 or Barke barley genotypes.

NIV, HT-2, and T2 analysis. For toxin extraction, each sample was finely ground in a mill with a $1-\mathrm{mm}^{2}$ mesh (Cyclotech, Foss Tecator; Thermo Scientic, Rockford, IL) and homogenized accord- ing to Barros et al. (3). A subsample of $25 \mathrm{~g}$ was extracted by mixing with $100 \mathrm{ml}$ of acetonitrile/water $(84: 16$, vol/vol), shaken for 2 $\mathrm{h}$ on a oscillatory shaker, then filtered through Whatman number 4 filter paper. Clean-up was carried out with a Mycosep 227 column (Romer Labs Inc., Union, MO). The filtrate $(8 \mathrm{ml})$ was transferred to a culture tube and slowly pressed into the interior of the tube with the rubber flange end turned down, until $6 \mathrm{ml}$ of the extract had passed through the column. Then, $1 \mathrm{ml}$ of the purified extract was transferred to a vial and evaporated to dryness under nitrogen at $60^{\circ} \mathrm{C}$ in a heating block (Thermo Scientific).

The detection of NIV was performed using the method described by Barros et al. (3). The dried residue obtained after Mycosep 227 column clean-up was dissolved in $400 \mu \mathrm{l}$ of methanol/water $(5: 95, \mathrm{vol} / \mathrm{vol})$, homogenized in a vortex mixer, and injected into the high-performance liquid chromatography (HPLC) system by full-loop injection technique (model 1100 pump; Hewlett Packard, Palo Alto, CA; and Rheodyne manual injector with a 50- $\mu$ l loop; Rheodyne, Cotati, CA). The HPLC system consisted of a Hewlett Packard model 1100 pump connected to a Hewlett Packard 1100 Series variable-wavelength detector and a data module Hewlett Packard Kayak XA (HP ChemStation Rev. A.06.01). Chromatographic separations were performed on a Luna C18 reversed-phase column (100 by $4.6 \mathrm{~mm}, 5-\mu \mathrm{m}$ particle size) connected to a SecurityGuard guard column $(4$ by $3.0 \mathrm{~mm})$ filled with the same phase. The mobile phase consisted of metha$\mathrm{nol} /$ water $(12: 88, \mathrm{vol} / \mathrm{vol})$, at a flow rate of $1.5 \mathrm{ml} / \mathrm{min}$. The detector was set at $220 \mathrm{~nm}$ with an attenuation of 0.01 AUFS. Quantification was relative to external standard of NIV (SigmaAldrich, St. Louis). Four working solutions to perform calibration were prepared with concentrations of NIV $0.5,1,2$, and $4 \mu \mathrm{g} / \mathrm{ml}$ in methanol/water (5:95). The calibration curve showed good linearity for the mycotoxin, with an $R^{2}=0.99$. The detection limit was $50 \mathrm{ng} / \mathrm{g}$ based on a signal-to-noise ratio 3:1.

The dried residue was derivatized as previously described for T2 and HT- 2 toxins by Visconti et al. (31). DMAP solution $(50 \mu \mathrm{l}$ at $0.325 \mu \mathrm{g} / \mu \mathrm{l}$ in toluene) followed by $50 \mu \mathrm{l}$ of 1 -AN reagent $(0.3$ $\mu \mathrm{g} / \mu \mathrm{l}$ in toluene) were added to the dried residue. The vial was closed and mixed by vortex for $1 \mathrm{~min}$. The mixture was left to react

Table 2. Analyses of variance of the disease incidence and severity of wheat and barley genotypes inoculated with Fusarium poae

\begin{tabular}{lrcrr}
\hline Source & df & Mean squares & $\boldsymbol{F}$ value & $\boldsymbol{P}$ value \\
\hline Incidence & & & & \\
$\quad$ Year (Y) & 2 & 0.05 & 139.19 & 0.0002 \\
Genotype (G) & 7 & 0.05 & 109.45 & $<0.0001$ \\
Isolate (I) & 4 & 0.003 & 7.83 & $<0.0001$ \\
Block (B) & 2 & 0.001 & 3.10 & 0.0470 \\
Y $\times$ G & 14 & 0.03 & 59.51 & $<0.0001$ \\
Y $\times$ I & 8 & 0.003 & 4.59 & $<0.0001$ \\
I $\times$ G & 28 & 0.003 & 3.17 & $<0.0001$ \\
Y $\times$ G $\times$ I & 56 & 0.003 & 2.13 & 0.0001 \\
Severity & & & & \\
Year (Y) & 2 & 0.80 & 295.44 & $<0.0001$ \\
Genotype (G) & 7 & 0.53 & 80.05 & $<0.0001$ \\
Isolate (I) & 4 & 0.05 & 7.38 & $<0.0001$ \\
Block (B) & 2 & 0.01 & 1.27 & 0.2836 \\
Y $\times$ G & 14 & 0.24 & 35.91 & $<0.0001$ \\
Y $\times$ I & 8 & 0.03 & 3.85 & 0.0003 \\
I $\times$ G & 28 & 0.02 & 3.18 & $<0.0001$ \\
Y $\times$ G $\times$ I & 56 & 0.01 & 1.70 & 0.0040 \\
\hline
\end{tabular}

Table 1. Temperature, relative humidity (RH), and accumulated precipitation during 2009, 2010, and 2012 growing seasons (from inoculation to harvest) ${ }^{\mathrm{a}}$

\begin{tabular}{llccccc}
\hline & \multicolumn{3}{c}{ Temperature $\left({ }^{\circ} \mathbf{C}\right)$} & & \\
\cline { 2 - 4 } Year & \multicolumn{1}{c}{ Average } & Average minimum & Average maximum & & RH\% (average) & Precipitation (mm) \\
\hline 2009 & $16.6(11.0-22.3)$ & $9.2(0.8-16.9)$ & $23.7(16.0-31.5)$ & & $66.8(38.0-95.5)$ & 171.1 \\
2010 & $16.6(9.4-23.3)$ & $8.9(-1.1-16.0)$ & $24.2(16.8-34.5)$ & & $67.2(43.0-92.5)$ & 131.5 \\
2012 & $18.0(11.6-23.8)$ & $11.6(4.0-18.5)$ & $24.6(16.0-31.9)$ & & $72.2(57.0-94.8)$ & 241.5 \\
\hline
\end{tabular}

a Weather station was located $100 \mathrm{~m}$ from the experimental site and data were taken every $30 \mathrm{~min}$. 
for $15 \mathrm{~min}$ at $50^{\circ} \mathrm{C}$ in a heater block and then cooled in ice for 10 min. The reaction mixture was dried under a gentle stream of nitrogen at $50^{\circ} \mathrm{C}$, reconstituted with $1,000 \mu \mathrm{l}$ of an acetonitrile/water (70:30, vol/vol) mixture, and homogenized in a vortex mixer for 30 $\mathrm{s}$. The solution $(50 \mu \mathrm{l})$ was injected into the HPLC system by the full-loop injection technique (Hewlett Packard model 1100 pump and Rheodyne manual injector with a 50- $\mu$ loop). Chromatographic separations were performed on a Phenyl-Hexyl Luna column (150 by $4.6 \mathrm{~mm}$ i.d., 5 - $\mu \mathrm{m}$ particle size; Luna-Phenomenex, Torrance, CA) connected to a precolumn Security Guard (20 by 4.6 mm i.d., 5 - $\mu \mathrm{m}$ particle size; Phenomenex). The flow rate of the mobile phase was $1.0 \mathrm{ml} / \mathrm{min}$. A binary gradient was applied as follows: the initial composition of the mobile phase, $70 \%$ acetonitrile and $30 \%$ water, was kept constant for $5 \mathrm{~min}$, and then the acetonitrile content was linearly increased to $85 \%$ in $10 \mathrm{~min}$ and kept constant for $10 \mathrm{~min}$. Finally, to clean the column, the amount of acetonitrile was increased to $100 \%$ in 2 min and kept constant for $5 \mathrm{~min}$. The mycotoxins were detected by fluorometric detection (Hewlett Packard model 1046A programmable fluorescence detector) at $381 \mathrm{~nm}$ (excitation wavelength) and $470 \mathrm{~nm}$ (emission wavelength) and quantified by a data module Hewlett Packard Kayak XA (HP ChemStation Rev. A.06.01). The limit of detection for the method was $25 \mu \mathrm{g} / \mathrm{kg}$ for T-2 and HT-2, based on a signalto-noise ratio of 3:1.

\section{Results}

Analyses from control blocks indicated no symptom development by $F$. poae isolates and the absence of mycotoxins in the control blocks was also confirmed. However, we observed 1 to $5 \%$ contamination with F. graminearum on some blocks for 2012 .

Significant differences were detected for the combined analysis of genotype-isolate, year-genotype, year-isolate, and year-genotype-isolate interactions for both incidence and disease severity, and block for incidence (Table 2). All genotypes tested showed symptoms with all the isolates used for the experiments, and significant differences for genotype-isolate were found (Table 2). In general, the barley genotypes used in our study were more resistant than the wheat genotypes for both incidence and severity, and Apogee was the most susceptible genotype compared with all the genotypes tested (Fig. 1). In the same way, the year-genotype (Fig. 2)

\section{A}

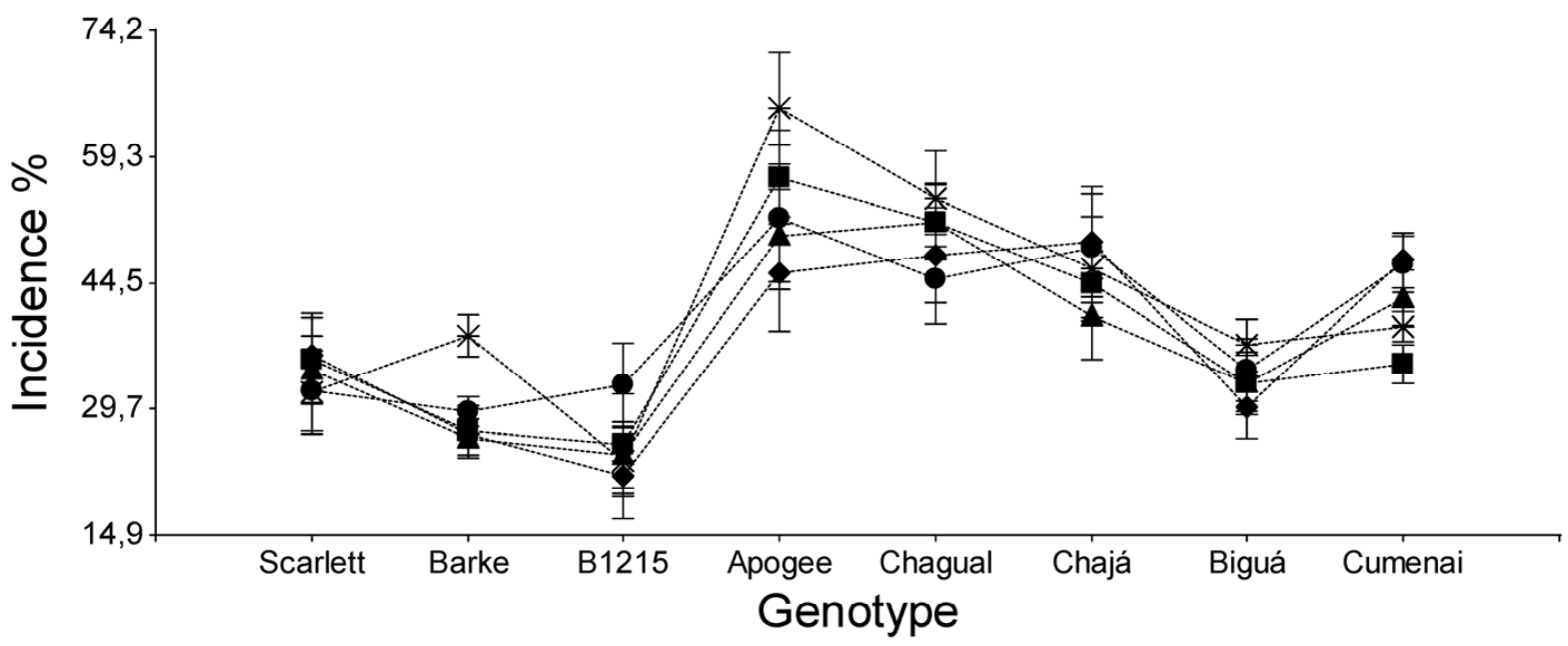

B

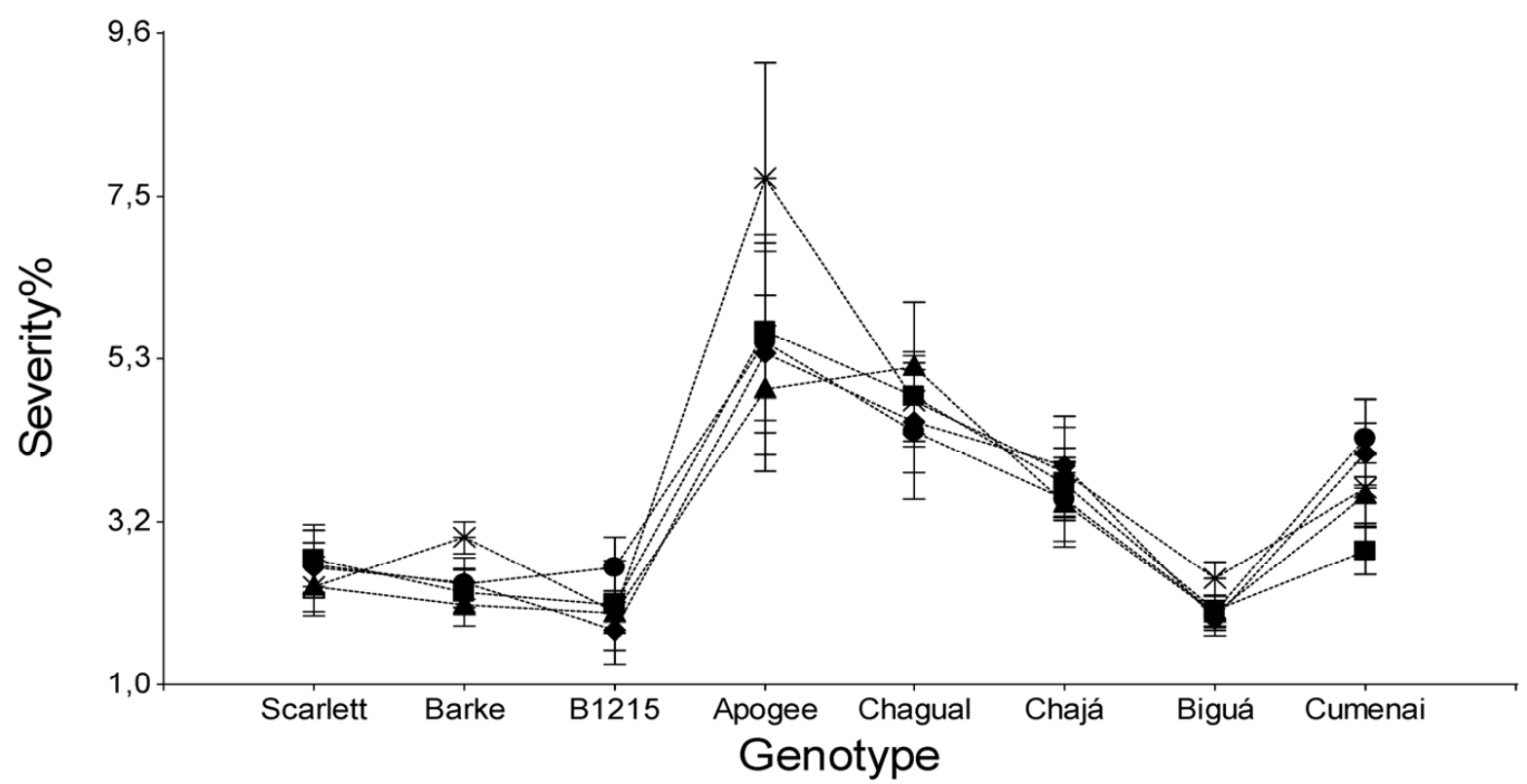

Fig. 1. Genotype-isolate interaction for A, incidence and B, severity of Fusarium head blight caused by Fusarium poae on wheat and barley across years. HSu1a ( $\mathbf{\square})$, MICAT01 $(\bullet)$, MICAT08 $(\mathbf{\Delta})$, TSa1a $(\bullet)$, and TSS1a (*). Scarlett, Barke, and B1215 are barley genotypes. Apogee, Chagual, Chajá, Biguá, and Cumenai are wheat genotypes. 
and year-isolate (Fig. 3) interactions were significant, with 2009 having greater symptom development.

For 2009, Apogee had the greatest incidence and severity (86 and $13.6 \%$, respectively) with isolate TSS1a and Barke had the lowest (26.6 and 2.2\%, respectively) with isolate HSu1a. For 2010, Apogee had the greatest incidence and severity (55 and 5.6\%, respectively) for with TSS1a and the least (0 and 0\%, respectively) for B1215 with MICAT01. Finally, in 2012, Apogee again had the greatest incidence and severity (53.3 and $3.9 \%$, respectively) with TSS1a and Barke the lowest (15 and $0.9 \%$, respectively) with MICAT01 (data not shown).

Contrasts were all significant for incidence and only the contrast between Scarlett versus B1215 or Barke was not significant for severity. Apogee was more susceptible than the other wheat genotypes, wheat genotypes were more susceptible than barley genotypes, durum wheat genotypes were more susceptible than bread wheat genotypes, and Scarlett had greater symptom development per spike than the other barley genotypes.

T-2 and HT-2 toxins were not detected in any of the samples analyzed. NIV was detected in samples from the 2009 and 2010 harvest seasons but not from the 2012 harvest season. NIV was produced by all isolates in all genotypes, except for Barke barley.
In 2009, we found NIV in samples of Scarlett inoculated with HSula $(0.2 \mu \mathrm{g} / \mathrm{g})$ and TSS1a $(10.8 \mu \mathrm{g} / \mathrm{g}), \mathrm{B} 1215$ inoculated with TSa1a $(0.62 \mu \mathrm{g} / \mathrm{g})$, Apogee with HSula $(2.7 \mu \mathrm{g} / \mathrm{g})$, Chajá with HSu1a $(2.1 \mu \mathrm{g} / \mathrm{g})$, Biguá with MICAT01 $(16.1 \mu \mathrm{g} / \mathrm{g})$, and Chagual with TSS1a $(0.6 \mu \mathrm{g} / \mathrm{g})$. In 2010, NIV was detected only in samples of Chagual inoculated with TSS1a $(0.6 \mu \mathrm{g} / \mathrm{g})$ and Cumenai with MICAT08 $(0.3 \mu \mathrm{g} / \mathrm{g})$. The low number of samples with NIV did not allow us to perform a statistical analysis.

\section{Discussion}

F. poae pathogenicity shows genotype, isolate, and climatic dependence, and mycotoxin production (NIV) also varies according the year, genotype, and isolate.

Because tillage practices and crop residues were similar in the 3 years of this study, our results indicated that differences in climatic factors were sufficiently different to result in variation in disease symptoms. Other researchers have also found that environmental conditions play a fundamental role in Fusarium spp.-host interactions $(32,33)$.

F. poae isolates used in our study were capable of producing disease on all genotypes tested. Moreover, previous observations demonstrated that isolates obtained from wheat or barley grains
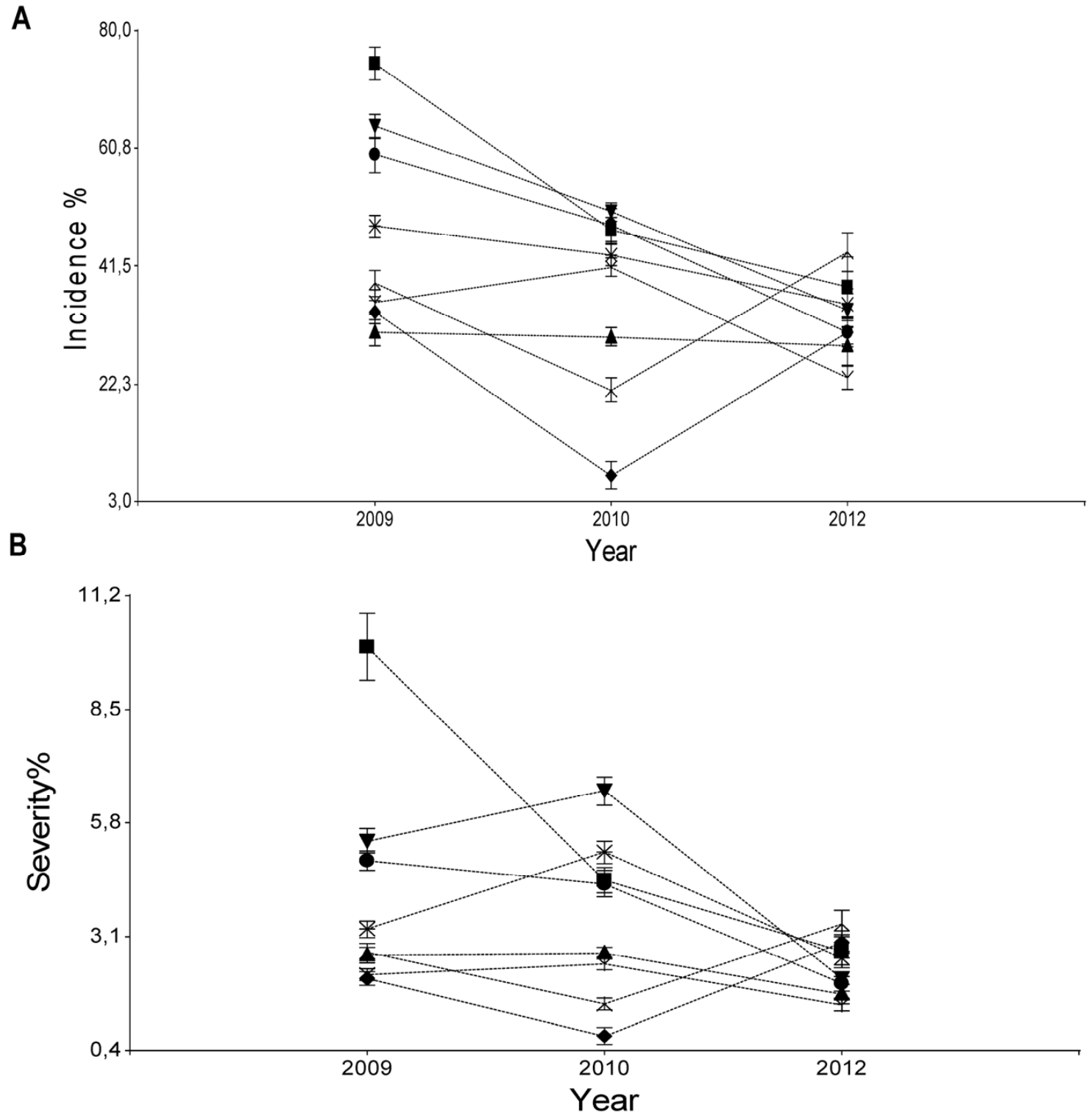

Fig. 2. Year-genotype interaction for A, incidence and B, severity of Fusarium head blight caused by Fusarium poae on wheat and barley. Apogee ( $\mathbf{\square})$, B1215 ( $\bullet$ ), Barke $(\boldsymbol{\Lambda})$, Biguá $(v)$, Chagual $(\boldsymbol{\nabla})$, Chajá $(\bullet)$, Cumenai $(*)$, and Scarlett $(\wedge)$. Scarlett, Barke, and B1215 are barley genotypes. Apogee, Chagual, Chajá, Biguá, and Cumenai are wheat genotypes. 
caused symptoms on both plant species, supporting previous observations that $F$. poae isolates are not host specific (29). This result is relevant for Argentina and other countries where wheat and barley cereals are cultivated near one another and with similar sowing dates, indicating the possibility of $F$. poae cross-infections between both crops.

The genotypes inoculated with $F$. poae developed different symptom severities, and wheat and barley genotypes differed significantly for incidence and severity, which agrees with other works $(2,32)$. The current study confirms that Apogee is very susceptible to $F$. poae, indicating that it could be an excellent genotype for studying not only $F$. poae-wheat interactions but also plant-pathogen interactions with other Fusarium spp. (22). Moreover, because FHB symptoms are related to climatic conditions, Apogee could be an excellent genotype to use as a positive FHB control in breeding programs.

Contrasts between wheat and barley genotypes demonstrated that the wheat genotypes used in our study are more susceptible than the barley ones. This result could be explained by the differences in temporal and spatial flowering patterns or the possibility of resistance genes present in barley but not in wheat genotypes.
Differences for incidence were observed for barley genotypes; Scarlett is the most widely grown barley genotype in Argentina and attention is needed in order to develop breeding programs to improve resistance to $F$. poae and other Fusarium spp. Durum wheat genotypes used in our study were more susceptible than bread wheat genotypes to $F$. poae, in accordance with other reports that used other Fusarium spp. for similar studies $(1,23,26)$.

Neither HT-2 nor T-2 toxins were detected in the grain samples analyzed. HT-2/T-2 production is not common in $F$. poae isolates (30) and was detected only in some wheat samples and in low concentrations by Vogelgsang et al. (32). In contrast, all F. poae isolates produced NIV, and the concentrations detected in wheat ranged between 0.2 and $16.1 \mu \mathrm{g} / \mathrm{g}$, and between 0.3 and $10.8 \mu \mathrm{g} / \mathrm{g}$ in barley. The high NIV values found in wheat and barley samples showed that $F$. poae could present a serious risk for wheat and barley products. Deoxynivalenol (DON), commonly produced by $F$. graminearum, is one of the principal quality problems of malting barley (27). Recently, Nielsen et al. (25) demonstrated that $F$. poae affects malting and brewing parameters, and that $F$. poae DNA showed a significant positive relationship with NIV. However, specific studies on the effect of NIV on beer are needed. Both

A

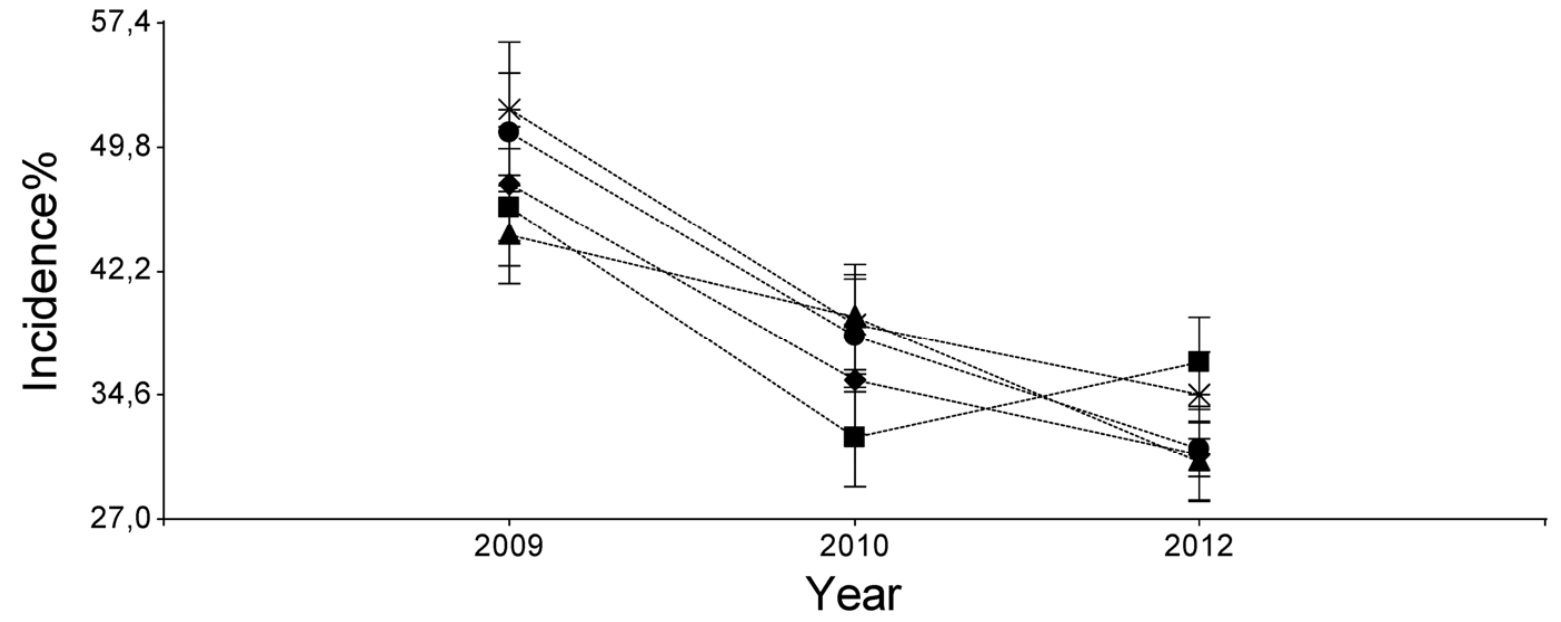

B

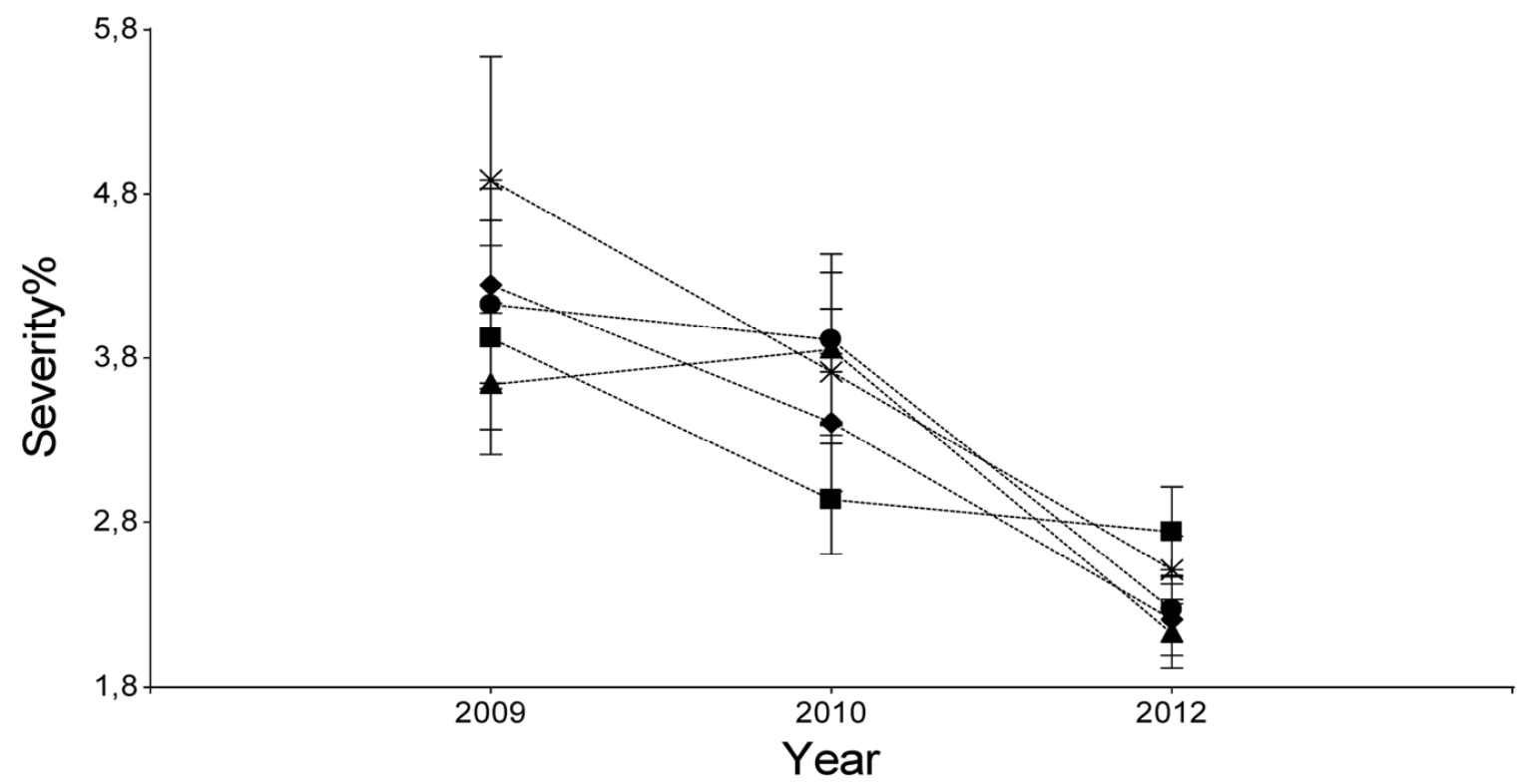

Fig. 3. Year-isolate interaction for A, incidence and B, severity of Fusarium head blight caused by Fusarium poae on wheat and barley. HSu1a ( $\mathbf{\square})$, MICAT01 ( $\bullet$ ), MICAT08 $(\boldsymbol{\Delta})$, TSa1a (O), and TSS1a (*). 
DON and NIV inhibit DNA and protein synthesis, inhibit cell metabolism, decrease cellular metabolism and cell proliferation, and induce apoptosis, with some analyses identifying NIV as more toxic than DON (24).

Vogelgsang et al. (32) found a high correlation between $F$. poae incidence and NIV grain content and suggested that this toxin might play a role in the $F$. poae pathogenesis. Unfortunately, our data on NIV concentration were not sufficient to test this suggestion. However, in 2009, we observed more symptom development and NIV grain content than in other years. Again, this situation could be explained by the climatic conditions. None of the grain samples of barley genotype Barke contained NIV, although F. poae isolates were capable of producing symptoms. One possibility that needs future work is that Barke possesses genes controlling NIV accumulation, as is the case for DON $(16,26)$.

Although the majority of pathogenicity and toxin studies use the $F$. graminearum-wheat or -barley interaction, the increased reported isolation of $F$. poae worldwide from different grain samples and the high capacity to produce NIV of this species justified more studies of these interactions, especially the less studied $F$. poaebarley.

\section{Acknowledgments}

We thank G. Mendivil and U. Troncoso for technical assistance in field experiments. This research was supported by FONCYT-SECYT PRH32 PICT 110 and PICT 030/2011, CONICET, and UNCPBA.

\section{Literature Cited}

1. Akinsanmi, O. A., Backhouse, D., Simpfendorfer, S., and Chakraborty, S. 2006. Pathogenic variation of Fusarium isolates associated with head blight of wheat in Australia. J. Phytopathol. 154:513-521.

2. Barreto, D., Carmona, M., Ferrazini, M., Zanelli, M., and Perez, B. 2004. Occurrence and pathogenicity of Fusarium poae in barley in Argentina. Cereal Res. Commun. 32:53-60.

3. Barros, G., García, D., Oviedo, S., Ramirez, L., Torres, A., and Chulze, S. 2008 Deoxynivalenol and nivalenol analysis in soybean and soy flour. World Mycotox. J. 1:263-266.

4. Bennet, J. W., and Klich, M. 2003. Mycotoxins. Clin. Microbiol. Rev. 16:497-516.

5. Birzele, B., Meier, A., Hindorf, H., Kramer, J., and Dehne, H. W. 2002. Epidemiology of Fusarium infection and deoxynivalenol content in winter wheat in the Rhineland, Germany. Eur. J. Plant Pathol. 108:667-673.

6. Bourdages, J. V., Marchand, S., Rioux, S., and Belzile, F. J. 2006. Diversity and prevalence of Fusarium species from Quebec barley fields. Can. J. Plant Pathol. 28:419-425.

7. Brennan, J. M., Leonard, G., Fagan, B., Cooke, B. M., Ritieni, A., Ferracane, R., Nicholson, P., Simpson, D., Thomsett, M., and Doohan, F. M. 2007. Comparison of commercial European wheat cultivars to Fusarium infection of head and seedling tissue. Plant Pathol. 56:55-64.

8. Buerstmayr, H., Legzdina, L., Steiner, B., and Lemmens, M. 2004. Variation for resistance to Fusarium head blight in spring barley. Euphytica 137:279290.

9. Castañares, E., Dinolfo, M. I., and Stenglein, S. A. 2012. Diversidad de especies del género Fusarium en granos de cebada y su potencial toxicológico. Pages 172-179 in: Cereales de invierno: investigación científico-técnica. S. Stenglein, M. V. Moreno, M. Cogliatti, W. L. Rogers, M. A. Carmona, and R. S. Lavado, eds. UNICEN Press, Buenos Aires.

10. Dinolfo, M. I., Barros, G., and Stenglein, S. A. 2012. Development of a PCR assay to detect the potential production of nivalenol in Fusarium poae. FEMS Microbiol. Lett. 332:99-104.

11. Dinolfo, M. I., Stenglein, S. A., Moreno, M. V., Nicholson, P., Jennings, P., and Salerno, G. L. 2010. ISSR markers detect high genetic variation among Fusarium poae isolates from Argentina and England. Eur. J. Plant Pathol. 127:483-491.

12. D'Mello, J. P. F., Placinta, C. M., and McDonald, A. M. C. 1999. Fusarium mycotoxins: A review of global implications for animal health, welfare and productivity. Anim. Feed Sci. Technol. 80:183-205.

13. Di Rienzo, J. A., Casanoves, F., Balzarini, M. G., González, L., Tablada, M., and Robledo, C. W. 2012. INFOSTAT. Grupo InfoStat, FCA, Universidad Nacional de Córdoba, Argentina.
14. Edwards, S. G. 2004. Influence of agricultural practices on Fusarium infection of cereals and subsequent contamination of grain by trichothecene mycotoxins. Toxicol. Lett. 153:29-35.

15. Fernandez, M. R., Zentner, R. P., DePauw, R. M., Gehl, D., and Stevenson, F. C. 2007. Impacts of crop production factors on Fusarium head blight in barley in eastern Saskatchewan. Crop Sci. 47:1574-1584.

16. Horsley, R. D., Schmierer, D., Maier, C., Kudrna, D., Urrea, C. A., Steffenson, B. J., Schwarz, P. B., Franckowiak, J. F., Green, M. J., Zhang, B., and Kleinholfs, A. 2006. Identification of QTLs associated with Fusarium head blight resistance in barley accession Clho 4196. Crop Sci. 46:145-156.

17. Infantino, A., Santori, A., and Shah, D. A. 2012. Community structure of the Fusarium complex on wheat seed in Italy. Eur. J. Plant Pathol. 132:499510 .

18. Isebaert, S., De Saeger, S., Devresse, R., Verhoeven, R., Maene, P., Heremans, B., and Haesaert, G. 2009. Mycotoxin-producing Fusarium species occurring in winter wheat in Belgium (Flanders) during 2002-2005. J. Phytopathol. 157:108-116.

19. Jestoi, M., Paavanen-Huhtala, S., Parikka, P., and Yli-Mattila, T. 2008. In vitro and in vivo mycotoxin production of Fusarium species isolated from Finnish grains. Arch. Phytopathol. Plant Prot. 41:545-558.

20. Legzdina, L., and Buerstmayr, H. 2004. Comparison of infection with Fusarium head blight and accumulation of mycotoxins in grain of hulless and covered barley. J. Cereal Sci. 40:61-67.

21. Leslie, J. F., and Summerell, B. A. 2006 The Fusarium Laboratory Manual. Blackwell Publishing, Oxford.

22. Mackintosh, C. A., Garvin, D. F., Radmer, L. E., Heinen, S. J., and Muehlbauer, G. J. 2006. A model wheat cultivar for transformation to improve resistance to Fusarium head blight. Plant Cell Rep. 25:313-319.

23. Miedaner, T., and Longin, C. F. H. 2014. Genetic variation for resistance to Fusarium head blight in winter durum material. Crop Pasture Sci. 65:46-51.

24. Minervini, F., Fornelli, F., and Flynn, K. M. 2004. Toxicity and apoptosis induced by the mycotoxins nivalenol, deoxynivalenol and fumonisin B1 in a human erythroleukemia cell line. Toxicol. In Vitro 18:21-28.

25. Nielsen, L. K., Cook, D. J., Edwards, S. G., and Ray, R. V. 2014. The prevalence and impact of Fusarium head blight pathogens and mycotoxins on malting barley quality in UK. Int. J. Food Microbiol. 179:38-49.

26. Rudd, J. C., Horsley, R. D., McKendr, A. L., and Elias, E. M. 2001. Host plant resistance genes for Fusarium head blight: Sources, mechanisms, and utility in conventional breeding systems. Crop Sci. 41:620-627.

27. Schwarz, P. B., and Horsley, R. D. 2006. Quality risks associated with the utilization of Fusarium head blight infected malting barley. J. Am. Soc. Brew. Chem. 64:1-7.

28. Stenglein, S. A. 2009. Fusarium poae: A pathogen that needs more attention. J. Plant Pathol. 91:25-36.

29. Stenglein, S. A., Dinolfo, M. I., Bongiorno, F., and Moreno, M. V. 2012. Response of wheat (Triticum spp.) and barley (Hordeum vulgare) to Fusarium poae. Agrociencia 46:299-306.

30. Thrane, U., Adler, A., Clasen, P., Galvano, F., Langseth, W., Lew, H., Logrieco, A., Nielsen, K. F., and Ritieni, A. 2004. Diversity in metabolite production by Fusarium langsethiae, Fusarium poae, and Fusarium sporotrichioides. Int. J. Food Microbiol. 95:257-266.

31. Visconti, A., Lattanzio, V. M. T., Pascale, M., and Haidukowski, M. 2005. Analysis of T-2 and HT-2 toxins in cereal grains by immunoaffinity cleanup and liquid chromatography with fluorescence detection. J. Chromatogr. A 1075:151-158.

32. Vogelgsang, S., Sulyok, M., Hecker, A., Jenny, E., Krska, R., Schuhmacher, R., and Forrer, H. R. 2008. Toxigenicity and pathogenicity of $F u$ sarium poae and Fusarium avenaceum on wheat. Eur. J. Plant Pathol. 122:265-276.

33. Xu, X., Nicholson, P., Thomsett, M. A., Simpson, D., Cooke, B. M., Doohan, F. M., Brennan, J., Monaghan, S., Moretti, A., Mule, G., Hornok, L., Beki, E., Tatnell, J., Ritieni, A., and Edwards, S. G. 2008. Relationship between the fungal complex causing Fusarium head blight of wheat and environmental conditions. Phytopathology 98:69-78.

34. Xu, X., Parry, D., Nicholson, P., Thomsett, M., Simpson, D., Edwards, S., Cooke, B., Doohan, F., Brennan, J., Moretti, A., Tocco, G., Mulè, G., Hornok, L., Giczey, G., and Tatnell, J. 2005. Predominance and association of pathogenic fungi causing Fusarium ear blight in wheat in four European countries. Eur. J. Plant Pathol. 112:143-154.

35. Yli-Mattila, T., Paavanen-Huhtala, S., Jestoi, M., Parikka, P., Hietaniemi, V., Gagkaeva, T., Sarlin, T., Haikara, A., Laaksonen, S., and Rizzo, A. 2008 Real-time PCR detection and quantification of Fusarium poae, F. graminearum, F. sporotrichioides and F. langsethiae in cereal grains in Finland and Russia. Arch. Phytopathol. Plant Prot. 41:243-260. 